\title{
Effects of an Education Program to Promote Advance Directive Completion in Local Residents
}

\author{
Miho Hamayoshi, $\mathbf{P h D}^{1,2}$
}

\author{
${ }^{1}$ Graduate School of Nursing, Osaka City University, Abeno, Osaka, Japan \\ 2 Department of Nursing, Bukkyo University School of Health Sciences, Nakagyo-ku, Kyoto, Japan
}

Purpose: An educational program was developed to facilitate advance directive (AD) completion, using the situation of end-of-life care for people with dementia. The aim of the study was to examine the effects on AD completion rates of an education program conducted for local community residents.

Methods: The design was a quasi-experimental study with intervention and control groups, respectively. The study population included local welfare officers from two cities in Osaka Prefecture, Japan, of whom 81 persons were allocated to an intervention group and 60 persons to a control group. A 70-minute intervention program was performed twice for the intervention group. Primary outcomes included AD completion and intention to complete an $\mathrm{AD}$, as indicated by binary "Yes" or "No" responses, and secondary outcomes included knowledge of AD, attitudes towards $\mathrm{AD}$, and knowledge of dementia.

Results: The intervention group exhibited a significant increase in the number of people who completed an AD from the baseline assessment compared to the four-month reassessment (odds ratio $=5.0,95 \%$ confidence interval $=1.0$ 25.0, $\mathrm{p}=0.04)$. The results showed that the interactions between group and time were statistically significant for scores of both the AD Attitude Survey Test $(\mathrm{F}=4.1, \mathrm{p}=0.04)$ and the Dementia Knowledge Scale $(\mathrm{F}=4.6, \mathrm{p}=0.04)$.

Conclusions: The results suggest that this education program to facilitate $\mathrm{AD}$ completion may promote 1) $\mathrm{AD}$ completion, 2) favorable attitudes towards $\mathrm{AD}$, and 3) knowledge of dementia among local residents.

Keywords: advance directives, end-of-life care, dementia

Author for correspondence: Miho Hamayoshi, $\mathrm{PhD}$

Nijo Campus, Bukkyo University, 7, Higashitoganoo-cho, Nishinokyo, Nakagyo-ku, Kyoto 604-8418

E-mail: hamayoshi@bukkyo-u.ac.jp

Received for publication 12 March 2014 and accepted in revised form 6 June 2014

(C) 2014 The Japan Primary Care Association 


\section{BACKGROUND}

Among Organization for Economic Co-operation and Development (OECD) nations, 14 million people aged 60 years and over are reported to suffer from dementia according to a 2009 estimate. ${ }^{1}$ In Japan, this number surpassed an estimated 3.05 million in $2012,{ }^{2}$ with the prevalence of dementia steadily increasing with advancing age. In recent years, there has been research on end-of-life care for elderly patients with dementia, $^{3-5}$ which identified the necessity of advance directives (ADs) for such persons. ${ }^{6,7} \mathrm{An} A D$ is defined as a document that establishes directives for treatment preferences during end-of-life care and designates a proxy decision maker. ${ }^{8}$

In the United States, ADs were enacted into law by the 1990 Patient Self-Determination Act. This legislation recognizes the right to self-determination of the patient, and $\mathrm{AD}$ completion is currently being established as a nursing standard of care for elderly patients. ${ }^{9}$ However, even in the United States, AD completion rates are not high, and interventions to facilitate $\mathrm{AD}$ completion through randomized clinical trials have been undertaken in recent decades. ${ }^{10-12}$

According to a research report by the Japanese Ministry of Health, Labour and Welfare concerning end-of-life care, ${ }^{13} 69.7 \%$ of the general population endorsed the statement "I agree that a document like a living will should give instructions about medical care." Although those in favor of ADs are increasing in number, ${ }^{13}$ research on methods to promote ADs has not yet clarified the best approach in Japan.

Previous research on education promoting AD completion in Western countries has demonstrated the necessity of providing this education through medical professionals, ${ }^{14}$ or of including interactions with others. ${ }^{15,16}$ Current research suggests that multimodal intervention is needed for improving $\mathrm{AD}$ completion rates. Incorporating models of health behavior change to promote ADs ${ }^{17-19}$ and the Theory of Planned Behavior (TPB) have both been used to complete advance care planning and ADs. ${ }^{20}$ The author developed an $\mathrm{AD}$ completion promotion program that uses a behavior prediction model based on the TPB, where "behavioral intention" and "subjective norms" shape "perceived behavioral control." These three elements working together can positively support undertaking goal-oriented actions. The programs based on this theory can help form proactive attitudes towards $\mathrm{AD}$ completion with the purpose of encouraging participants to take action.

It is desirable that an $\mathrm{AD}$ should be completed at a stage when people's decision-making abilities are competent so that the documents can accurately indicate well-considered wishes for their future endof-life care. ${ }^{21,22}$ It is necessary that this be done before they become "old-old" to thereby adequately reflect their actual intentions.

The aim of this study was to examine the effects on local community residents, without cognitive decline, of an education program based on the Theory of Planned Behavior to determine AD completion rates, attitudes towards $\mathrm{AD}$, and knowledge of dementia.

\section{METHODS}

\section{Procedure and participants}

The study design was a non-randomized quasiexperimental study with an intervention and a control group. The data were collected from June to December 2012, inclusive.

The study participants were local welfare officers from two cities in Osaka, Japan: Neyagawa, as the intervention group, and Izumiotsu as the control group. Local welfare officers are community officials appointed by the Minister of Health, Labour and Welfare who support elderly people living alone, with the number of these proportional to the municipality's population. They are usually retired employees and housewives, with an average age of over 60 years.

The study participant flow chart is shown in Figure 1. On $1^{\text {st }}$ July 2012 , the population of Neyagawa was 242,792 and that of Izumiotsu was 77,350; the total number of local welfare officers of Neyagawa was 368 , and that of Izumiotsu was 90, respectively. Welfare officers from two districts in Neyagawa and all 90 officers in Izumiotsu were invited to participate in this study. The final study population comprised 106 officers from Neyagawa and 63 from Izumiotsu. The follow-up measurements were collected from 81 subjects in Neyagawa, and 60 in Izumiotsu (see Figure 1). Because the concept of ADs is not common knowledge 
Figure 1. Derivation of study participants

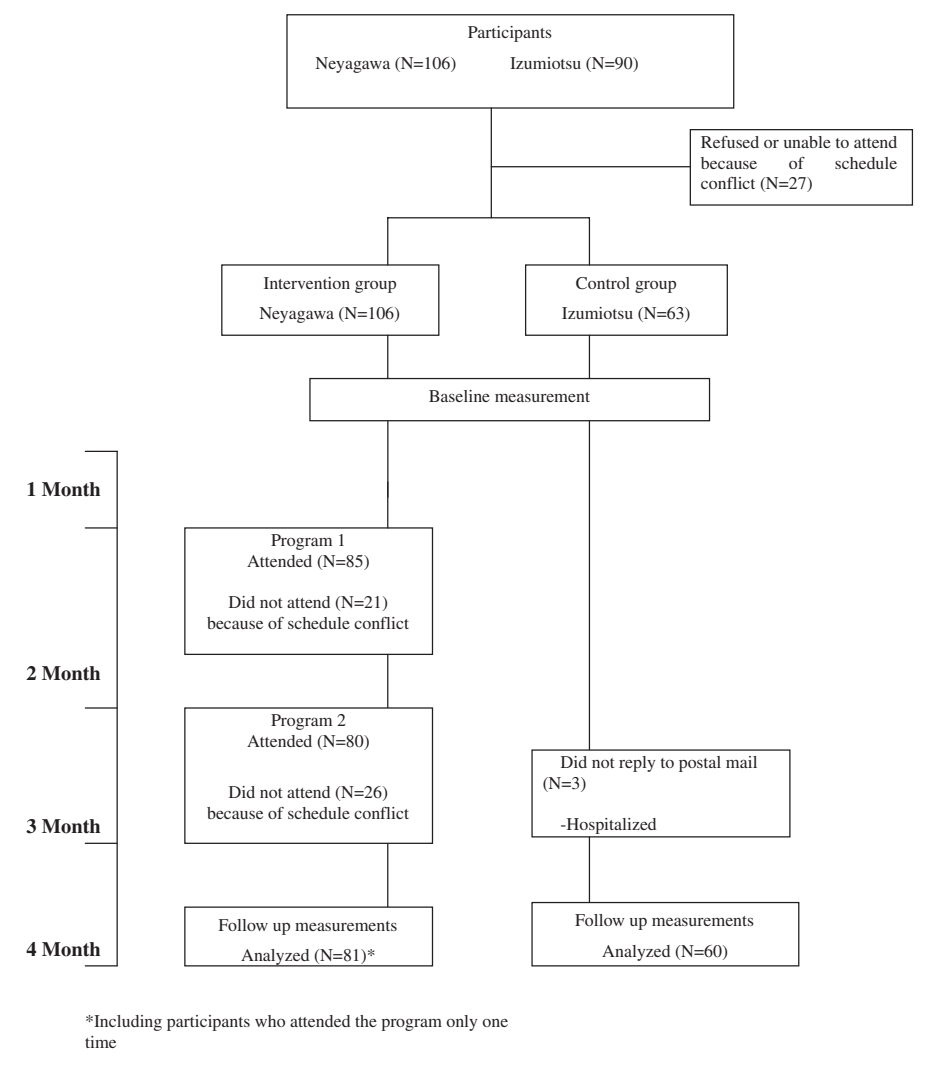

in Japan, a 60-minute lecture, the contents of which were related to ADs and dementia, was provided to both the intervention and control groups before baseline data collection. Initial baseline data were collected immediately after this lecture, and the follow-up data were collected four months after baseline at a meeting for the intervention group and via postal mail for the control group. The data collection method differed between groups because there was no regular meeting at the time of follow-up for the control group.

All data were collected via a self-administered written questionnaire. The four-month endpoint was chosen in keeping with other studies on $\mathrm{AD}$ which had similar endpoints. $^{12}$

\section{Statistical analysis}

Based on applied multiple regression analysis ${ }^{23}$ for a significance level $\alpha$ of 0.05 and detection power of 0.8 , a sample size of 63 individuals per group was considered to be effective for detecting a moderate size effect. Accordingly, a total of 126 individuals were chosen as the sample population size. Eighty indi- viduals were recruited for both the intervention group and the control group, with an assumed 20\% drop out rate.

\section{Outcome measures}

\section{1) Primary outcome}

The primary outcomes were measured via two indicators of $\mathrm{AD}$ completion and intention to complete an $\mathrm{AD}$, which were the responses to the questions "Did you complete an AD?" and "Do you think that you will complete an AD?", respectively; these questions were scored as 1 for "Yes" or 0 for "No." In this study, an $\mathrm{AD}$ was defined as a document that established directives for treatment preferences during end-of-life care and which designated a proxy decision maker. An $\mathrm{AD}$ booklet was distributed and explained at the time of the baseline lecture about ADs and dementia.

\section{2) Secondary outcome}

The secondary outcomes included knowledge of ADs, attitudes towards ADs, and knowledge about dementia. Knowledge of ADs and positive attitudes towards ADs were anticipated to be closely associated with $\mathrm{AD}$ 
completion rates from the results of our previous study. ${ }^{24}$ In addition, it was considered that knowledge about dementia and $\mathrm{AD}$ completion would be closely associated, because knowledge about dementia promotes recognition of the disabling of self-determination caused by it.

Knowledge about ADs was measured by the eight items from the Japanese version ${ }^{25}$ of the AD Knowledge Test. ${ }^{26}$ The original AD Knowledge Test is scored in terms of binary, correct/incorrect responses to items; the scale is calculated by giving each correct item a score of 1 and each incorrect item a score of 0 . Higher scores indicate a greater extent of knowledge with the range of scores being from 0 to 10 , inclusive. The internal consistency of the original scale, using Cronbach's alpha, was $0.79 .{ }^{27}$ Prior to the present study, these scales were translated into Japanese with the consent of the authors, and which was administered to 102 members of an elderly association as a pretest. ${ }^{25}$ As a result of verifying the correlation coefficients between each item and the total scale (I-T coefficients), two items were removed from the AD Knowledge Test whose coefficients fell below 0.3 ; finally eight items were used for the Japanese version of the scale, with a Cronbach's alpha of 0.67 from the preliminary data. ${ }^{25}$ Attitudes towards ADs was measured by the 11 items of the Japanese version ${ }^{23}$ of the AD Attitude Test. ${ }^{25}$ The original AD Attitude Test items are scored ranging from 1 (strongly agree) to 4 (strongly disagree); for purposes of analysis, 'strongly agree' and 'agree' responses were combined into one 'agree' response category and 'disagree' and 'strongly disagree' were combined into one 'disagree' response category. The response to each item was scored as 1 for 'agree' or 0 for 'disagree'. The total scores range from 0 to 13 points, and higher scores indicate more favorable attitudes toward ADs. The internal consistency of the original scale, using Cronbach's alpha, was $0.80 .{ }^{26}$ Prior to the present study, as a result of verifying the correlation coefficients between each item and the total scale (I-T coefficients), two items were removed from the AD Attitude Scale whose coefficients fell below 0.3 and 11 items were used for the Japanese version of the scale. Cronbach's alpha was 0.86 in the preliminary data. ${ }^{25}$
Knowledge about dementia was measured by the Dementia Knowledge Test. ${ }^{26}$ This uses a three-point scale of "agree", "disagree", and "I don't know." The response to each item was scored as 1 for 'agree' or 0 for either 'disagree' or 'I don't know'. The total number of correct responses indicates the extent of knowledge about dementia. Scores range from 0 to 15 points and higher scores show greater knowledge about dementia. The Cronbach's alpha of the Dementia Knowledge Test was $0.71 .^{27}$

\section{AD Completion Program}

The AD Completion Program for the intervention group used the framework of a behavior prediction model based on the Theory of Planned Behavior. ${ }^{28} \mathrm{~A}$ 70-minute intervention program was performed twice for the participants in the intervention group. This full program consisted of two lectures including the following themes: "Who will have durable power of attorney if you get dementia?" and "When a family member cannot eat food, what kinds of decisions do you have?"

Explanations were provided about a proxy decision maker and the requirement of a percutaneous endoscopic gastrostomy (PEG) tube towards the end of life. Each program consisted of three elements according to the TPB: a short lecture aimed at facilitating favorable attitudes towards ADs; use of a case example scenario to facilitate subjective behavioral norms; and group work or feedback aimed at facilitating perceived behavioral control, so that participants recognized behavioral decision-making processes (see Table 1). An AD booklet describing how to fill in the form for an $\mathrm{AD}$ was distributed to both control and intervention groups at the time of the baseline assessment, and the process was explained in the knowledge portion of the lecture.

The intervention was conducted after regular meetings of the local welfare officers in citizen centers.

\section{Ethical approval}

Participants gave informed consent via signed documents after a thorough explanation of the study. Study subjects were allowed to withdraw from the study at any time. The study was approved by the Ethics 
Table 1. Program protocol

\begin{tabular}{|c|c|c|c|}
\hline $\begin{array}{r}\text { Framework of } \\
\text { Program }\end{array}$ & $\begin{array}{l}\text { Attitude toward behavior } \\
\text { (Facilitating favorable } \\
\text { attitudes to ADs) }\end{array}$ & $\begin{array}{c}\text { Subjective norm } \\
\text { (Facilitating subject } \\
\text { behavioral norms) }\end{array}$ & $\begin{array}{l}\text { Perceived behavioral control } \\
\text { (Facilitating behavioral } \\
\text { decision-making processes) }\end{array}$ \\
\hline \multirow{2}{*}{$\begin{array}{l}\text { Who will have durable } \\
\text { power of attorney if you } \\
\text { develop dementia? }\end{array}$} & $\begin{array}{l}\text { Short lecture about acquiring } \\
\text { AD-related information } \\
\text { (15 minutes })\end{array}$ & $\begin{array}{l}\text { Experiencing a scenario } \\
\text { to evoke an emotional } \\
\text { response, and individual } \\
\text { work ( } 25 \text { minutes) }\end{array}$ & $\begin{array}{l}\text { Building consensus with group } \\
\text { work and general feedback } \\
\text { (30 minutes) }\end{array}$ \\
\hline & $\begin{array}{l}\text { Durable power of attorney } \\
\text { \& its role in ADs. }\end{array}$ & $\begin{array}{l}\text { Uses a case example of a } \\
\text { scenario of necessary } \\
\text { decision-making for a } \\
\text { family member. }\end{array}$ & $\begin{array}{l}\text { Discussion about who is given } \\
\text { durable power of attorney and } \\
\text { why, conducted in groups. }\end{array}$ \\
\hline \multirow{2}{*}{$\begin{array}{l}\text { When a family member } \\
\text { cannot eat food what } \\
\text { kinds of decisions } \\
\text { do you have? }\end{array}$} & $\begin{array}{l}\text { Short lecture about acquiring } \\
\text { AD-related information } \\
\text { (15 minutes) }\end{array}$ & $\begin{array}{l}\text { Experiencing a scenario } \\
\text { to evoke an emotional } \\
\text { response, and individual } \\
\text { work ( } 25 \text { minutes) }\end{array}$ & $\begin{array}{c}\text { Building consensus with group } \\
\text { work and general feedback } \\
\text { (30 minutes) }\end{array}$ \\
\hline & $\begin{array}{l}\text { How it can become } \\
\text { impossible for a person to } \\
\text { eat \& undergo } \\
\text { percutaneous endoscopic } \\
\text { gastrostomy. }\end{array}$ & $\begin{array}{l}\text { Uses a case example of a } \\
\text { scenario where it has } \\
\text { become impossible for a } \\
\text { family member to eat. }\end{array}$ & $\begin{array}{l}\text { Discussion about the decision } \\
\text { from the family's perspectives, } \\
\text { conducted in groups. }\end{array}$ \\
\hline
\end{tabular}

Committee of the Graduate School of Nursing, Osaka City University.

\section{Statistical analysis}

Statistical analysis was performed using Statistical Analysis System (SAS) software version 9.2 (SAS Institute, Cary, NC, USA). The level of statistical significance was set with a $\mathrm{p}$-value of $<0.05$.

To compare characteristics at baseline between the two groups, the students t-test was used for continuous variables and $\chi^{2}$-tests for categorical variables. Odds ratios were calculated by logistic regression analysis adjusted for age and sex to find the primary outcomes of changes in $\mathrm{AD}$ completion behavior and intention between groups. Score changes in the AD Knowledge Test, AD Attitude Test, and Dementia Knowledge Scale were examined by repeated measures two-way analysis of variance (ANOVA) after adjusting for age and sex, using the SAS procedure "proc mixed" with pre- versus post-intervention (time) and intervention versus control (group), respectively.

\section{RESULTS}

\section{Characteristics of participants at baseline}

Characteristics of participants at baseline are shown in Table 2. The mean age of the study participants was 66.7 years $(\mathrm{SD}=6.5)$ for the intervention group and 66.1 years $(\mathrm{SD}=6.6$ ) for the control group; these were not significantly different. The percentage of females in the intervention group (85.1\%) was significantly higher than that in the control group (53.3\%). There were no significant differences between the groups in respect of educational background, a history of having been a family caregiver, experience in having discussed endof-life topics with family members, a history of serious illness, or the belief in a specific religion (see Table 2 ).

\section{Effects on primary outcomes}

At baseline, no participant in the intervention group and one participant in the control group had completed an AD. Fourteen participants in the intervention group and two participants in the control group had completed an $\mathrm{AD}$ at four-months of follow-up. The 
Table 2. Characteristics of participants at baseline $(N=141)$

\begin{tabular}{lccc}
\hline \multicolumn{1}{c}{ Characteristics } & $\begin{array}{c}\text { Intervention } \\
(\mathbf{n = 8 1 )}\end{array}$ & $\begin{array}{c}\text { Control } \\
(\mathbf{n = 6 0 )}\end{array}$ & $p$-value \\
\hline $\begin{array}{l}\text { Age, Mean (SD) } \\
\text { Years of experience as local welfare commissioners, Mean (SD) }\end{array}$ & $66.7(6.5)$ & $66.1(6.6)$ & $0.57^{2)}$ \\
Sex, n (\%) & $12.2(11.2)$ & $11.4(8.9)$ & $0.63^{2)}$ \\
$\quad$ Male & $9(11.1)$ & $27(45.0)$ & $<0.0001^{1)}$ \\
$\quad$ Female & $69(85.1)$ & $32(53.3)$ & \\
Education, n (\%) & & & \\
$\quad$ High school or lower & $36(44.0)$ & $28(46.6)$ \\
$\quad$ College or higher & $42(51.7)$ & $28(45.6)$ & $0.57^{1)}$ \\
Have experience as a family care giver, n (\%) & $67(82.7)$ & $48(76.1)$ & $0.33^{1)}$ \\
Have discussed end-of-life topics with family, $\mathbf{n}(\%)$ & $56(69.1)$ & $44(69.8)$ & $0.92^{1)}$ \\
Have suffered a serious illness or surgical operation, $\mathbf{n}(\%)$ & $14(17.2)$ & $14(22.2)$ & $0.38^{1)}$ \\
Have a specific religion, $\mathbf{n}(\%)$ & $24(29.0)$ & $11(17.1)$ & $0.09^{1)}$ \\
\hline
\end{tabular}

Note: 1) Chi-square test; 2) Student's $t$-test

Table 3. Group comparison of number of ADs completed and intention to complete an AD $(N=141)$

\begin{tabular}{|c|c|c|c|c|c|c|c|c|c|}
\hline & \multirow{2}{*}{ Group } & \multicolumn{4}{|c|}{ Baseline } & \multicolumn{4}{|c|}{ 4-month follow-up } \\
\hline & & $\mathbf{N}(\%)$ & OR & $95 \% \mathrm{CI}$ & $p$ value & N (\%) & OR & $95 \% \mathrm{CI}$ & $p$ value \\
\hline \multirow[t]{2}{*}{ AD completion ${ }^{\text {a) }}$} & Intervention $^{\text {a) }}$ & 0 & NA & NA & .96 & $14(17)$ & 5.0 & $1.0-25.0$ & .04 \\
\hline & Control & $1(1)$ & & & & $2(3)$ & & & \\
\hline \multirow{2}{*}{$\begin{array}{l}\text { AD intention-to- } \\
\text { complete }\end{array}$} & Intervention $^{\text {a) }}$ & $51(65)$ & 0.5 & $0.2-1.2$ & .07 & $65(81)$ & 2.0 & $0.8-4.9$ & .09 \\
\hline & Control & $47(79)$ & & & & $41(68)$ & & & \\
\hline
\end{tabular}

Note: Multivariate logistic regression analysis; Adjusted variables $=$ Age, Sex

NA: Not Analyzed; OR = Odds Ratio; $\mathrm{CI}=$ Confidence Interval

Age: $47-64$ years old $=$ Age $1 ; 65-69$ years old $=$ Age $2 ; 70-76$ years old $=$ Age 3

${ }^{\text {a) Missing Variable: } \mathrm{n}=1}$

intervention group showed a significant increase in the number of people who had completed an AD compared to the control group (odds ratio $=5.0,95 \%$ confidence interval $(\mathrm{CI})=1.0-25.0, \mathrm{p}=0.04)$.

For the intention to complete an $\mathrm{AD}$, the affirmative responses in the intervention group increased by 15 but decreased by six in the control group, when compared to their respective baseline values, although these findings were not statistically significant (odds ratio $=2.0,95 \% \mathrm{CI}=0.8-4.9, \mathrm{p}=0.09$; see Table 3).

\section{Effects on secondary outcomes}

To validate the effectiveness of the intervention program, pre-intervention and four-months post-inter- vention average scale scores were compared for the intervention group and the control group in terms of the changes in secondary outcomes, respectively.

The results showed that the interaction between group and time were statistically significant for scores of both the AD Attitude Survey Test $(F=4.1, p=0.04)$ and the Dementia Knowledge Scale $(\mathrm{F}=4.6, \mathrm{p}=0.04)$. Scores of the Attitude Survey Test increased in the intervention group (mean $=0.4, \mathrm{SD}=2.0$ ) but decreased in the control group (mean $=-0.5, \mathrm{SD}=1.4$ ); scores of the Dementia Knowledge Scale increased in the intervention group (mean $=1.1, \mathrm{SD}=2.2$ ) while those in the control group remained unchanged (mean $=-0.1, \mathrm{SD}=2.5)$ over time. 
Table 4. Change in AD Knowledge Scale, AD Attitude Scale, and Dementia Knowledge Scale $(N=141)$

\begin{tabular}{|c|c|c|c|c|c|c|c|c|}
\hline & \multirow{2}{*}{$\begin{array}{c}\text { Possible } \\
\text { score } \\
\text { Range }\end{array}$} & \multirow{2}{*}{ Group } & \multirow{2}{*}{$\mathbf{N}$} & \multicolumn{2}{|c|}{$\begin{array}{c}\text { Assessment period, } \\
\text { Mean (SD) }\end{array}$} & \multicolumn{3}{|c|}{ Effect } \\
\hline & & & & Baseline & 4-months & $\begin{array}{l}\text { Group, } \\
F \text { value }\end{array}$ & $\begin{array}{c}\text { Time, } \\
F \text { value }\end{array}$ & $\begin{array}{c}\text { Group } \times \text { Time, } \\
F \text { value }\end{array}$ \\
\hline AD Knowledge & 0-8 & Intervention $^{\text {a) }}$ & 81 & $6.5(1.2)^{\mathrm{a})}$ & $7.0(1.1)^{\mathrm{a})}$ & $10.1^{* *}$ & $7.0^{*}$ & 0.7 \\
\hline Scale & & Control & 60 & $6.1(1.4)$ & $6.4(1.4)$ & & & \\
\hline AD Attitude & 0-11 & Intervention ${ }^{\text {b) }}$ & 81 & $8.9(1.8)^{b)}$ & $9.3(1.8)^{\mathrm{a})}$ & 2.7 & 0.03 & $4.1^{*}$ \\
\hline Scale & & Control $^{\mathrm{c})}$ & 60 & $9.0(2.2)$ & $\left.8.5(2.2)^{b}\right)$ & & & \\
\hline Dementia Knowledge & $0-15$ & Interventiond) & 81 & $11.4(2.2)^{\mathrm{a})}$ & $12.6(2.0)^{\mathrm{c})}$ & $9.0^{*}$ & $3.9^{*}$ & $4.6^{*}$ \\
\hline Scale & & Control $^{\mathrm{e})}$ & 60 & $10.9(2.4)^{\mathrm{b})}$ & $10.9(2.5)^{\mathrm{b})}$ & & & \\
\hline
\end{tabular}

Note: Two-way repeated measures analysis of variance; Adjusted Variables = Age, Sex

a) Missing Variable: $\mathrm{n}=1$

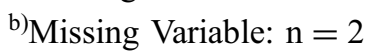

c) Missing Variable: $\mathrm{n}=3$

$*_{\mathrm{p}}<.05, * * \mathrm{p}<.001$

The AD Knowledge Test results showed that the interactions between group and time were not statistically significant $(\mathrm{F}=0.7, \mathrm{p}=.38$; see Table 4$)$.

\section{DISCUSSION}

Many previous studies have shown that AD completion rates have increased by $5 \%$ to $20 \%$ through intervention. ${ }^{12}$ The results of this study show similar results with a statistically significant increase from $0 \%$ to $17 \%$ in the intervention group, versus just $1 \%$ to $3 \%$ in the control group.

The results suggest that an $\mathrm{AD}$ completion promotion program may promote $\mathrm{AD}$ completion as well as favorable $\mathrm{AD}$ attitudes and improved knowledge about dementia among local residents.

These results also suggest that the present program using a TPB model can be effective in promoting AD completion among local residents. In particular, group work or interaction counseling with healthcare providers demonstrated a high efficacy in promoting an increase in the $\mathrm{AD}$ completion rate, which was consistent with previous studies. ${ }^{29-31}$

One possible reason for the score increases on the AD Attitude Survey and Dementia Knowledge Test was that the program focused on dementia issues specifically using case scenarios. After acquiring accurate knowledge about dementia, and considering potential problems with it, participants could evaluate for themselves the necessity for creating an $\mathrm{AD}$ and could also develop positive attitudes towards them.

One strength of the present study is that it is one of only a few intervention research investigations related to $\mathrm{AD}$ completion conducted in Japan that has established a target comparison group. Reported results of systematic reviews suggest that there is no evidence for increased completion rates in previous studies that used only knowledge providing-type interventions. ${ }^{11,12,31}$ Accordingly, in the present study a program was developed using the TPB as a framework and its efficacy was evaluated. The results showed that AD completion behavior significantly increased in the intervention groups, as did proactive attitudes toward ADs. Intervention effectiveness was low only for the knowledge-provision and paper medium approach. Having an interactive outreach likely leads to improved $\mathrm{AD}$ completion rates, results that are consistent with those of previous studies. ${ }^{15,16,28}$

A second strength of this study was the high adherence of participants to the intervention. Those in the intervention group who agreed to the study but did not attend were absent because of scheduling conflicts but not because of program refusal. There were no participants who refused the program in the present study. Thus, this type of program appears acceptable to Japanese citizens.

There were several limitations of the present study. One 
limitation is that the $\mathrm{AD}$ completion rate, the primary outcome, was based on self-reports, as other studies have also pointed out. ${ }^{11,12,14}$

A second limitation of the study is that the study population was composed of local welfare officers of just two cities, limiting the generalizability of the results. This group might have more knowledge about guardians or elderly suffering from dementia compared to the general public. Although $\mathrm{AD}$ completion was increased in the intervention locations, this study was not a randomized controlled trial (RCT). There is also a limit to such generalization because of the differences of the subject baseline demographic information between the two cities, and with the intervention group having a significantly greater proportion of females. Since there was a suggestion that woman are more likely to complete an $\mathrm{AD}$, as in our previous study, ${ }^{25}$ the influence of this in the present research must be considered. RCT or cluster RCT research designs have been conducted in other countries that have evaluated the efficacy of interventions for $\mathrm{AD}$ completion, and intervention evaluations in which uniformity in research populations is attempted are also becoming more numerous. ${ }^{11,30-32}$ To more rigorously confirm the effects of this program in the Japanese population, several future residential or outpatient studies should adapt a RCT or cluster RCT design.

A third limitation of this study was in the control group assessments. Replying by mail may have promoted a more negative attitude to $\mathrm{AD}$ completion.

\section{CONCLUSIONS}

The AD completion promotion program developed in the present study appeared to be effective in promoting AD completion among local residents. Furthermore, the creation of positive attitudes towards ADs appeared to encourage $\mathrm{AD}$ completion. This was one of the first intervention studies in Japan related to AD completion, and it is hoped that larger studies in the development of promotion and completion of ADs are undertaken hereafter.

\section{Acknowledgements}

The author would like to thank the participants in this study including the local welfare officers of Neyagawa and Izumiotsu in Osaka. Professors A Kono and M Shirai of the Graduate School of Nursing, Osaka City University are gratefully acknowledged for their significant advice.

This study was funded by The Yuumi Memorial Foundation of Home Health Care, 2012 (Miho Hamayoshi).

\section{References}

1 Wimo A, Linus J, John B, Martin P, Bemgt W: The worldwide economic impact of dementia 2010. Alzheimers Dement. 2013;19:1-11.e3.

2 Ministry of Health, Labour and Welfare: http:// www.mhlw.go.jp/english/. 2014.03/10.

3 Gillick MR: Rethinking the role of tube feeding in patients with advanced dementia. N Engl J Med. 2000;342:206-210.

4 Aita K, Takahashi M, Miyata M, Hiroaki M, Ichiro

K, Thomas EF: Physician's attitudes about artificial feeding in older patients with severe cognitive impairment in Japan: a qualitative study. BMC Geriatr. 2007;7:22.

5 Finucane TE, Christmas C, Travis K: Tube feeding in patients with advanced dementia: a review of the evidence. JAMA. 1999;282:1365-1370.

6 Rempusheski VF, Hurley AC: Advance directives and dementia. J Gerontol Nurs. 2000;10:27-34.

7 Harvey M: Advance directive \& severe dementia. J Med Philos. 2006;31:47-64.

8 Emanuel LL, Barry MJ, Stoeckle JD, Ettelson LM: Advance directives for medical care-A care for greater use. N Engl J Med. 1991;324:889-895.

9 Mitty EL, Ramsey G: Advance Directives. Geriatric Nursing Protocols for Best Practice. $2^{\text {nd }}$ ed. New York: Springer Publishing Company, 2008, 256-291.

10 Molloy DW, Guyatt GH, Russo R, et al: Systematic implementation of an advance directive program in nursing homes: a randomized controlled trial. JAMA. 2000;283:1437-1444.

11 Bravo G, Dubois MF, Wagneur B: Assessing the effectiveness of interventions to promote advance directives among older adults: A systematic review and multi-level analysis. Soc Sci Med. 2008;67:11221132.

12 Durbin CR, Fish AF, Bachman JA, Smith KV: Systematic review of educational interventions for 
improving advance directive completion. J Nurs Scholarsh. 2010;42:234-241.

13 Ministry of Health, Labour and Welfare: http:// www.mhlw.go.jp/stf/shingi/2r9852000000vj79.html, 2014.03/10.

14 Pearlman RA, Starks H, Cain KC, Cole WG: Improvements in advance care planning in the Veterans Affairs System: results of a multifaceted intervention. Arch Intern Med. 2005;165:667-674.

15 Ramsaroop SD, Reid MC, Adelman RD: Completing an advance directive in the primary care setting: what do we need for success? J Am Geriatr Soc. 2007;55:227-283.

16 Jezewski MA, Meeker MA, Sessanna L, Finnell DS: The effectiveness of interventions to increase advance directive completion rates. J Aging Health. 2007;9:519-537.

17 Kristen LP, Steven PD, Rebecca SA: A comparison of two interventions to increase completion of advance directives. Clin Gerontol. 2010;33:49-61.

18 Fried TR, Bullock K, Iannone L, O'Leary JR: Understanding advance care planning as a process of health behavior change. J Am Geriatr Soc. 2009;57: 1547-1555.

19 Westley C, Briggs LA: Using the stages of change model to improve communication about advance care planning. Nurs Forum. 2004;39:5-12.

20 Kataoka-Yashiro MR, Yancura LA, Page V, Inouye J: Advance care planning decision making among Asian Pacific Islander family caregivers of Stage 4 to 5 chronic kidney disease patients on hemodialysis: A focus group study. J Hosp Palliat Nurs. 2011;13:426-435.

21 Teno JM, Gruneir A, Schwartz Z, Nanda A, Wetle $\mathrm{T}$ : Association between advance directives and quality of end-of-life care: A national study. J Am Geriatr Soc. 2007;55:189-194.
22 Silveria MJ, Kim SYH, Langa KM: Advance directives and outcomes of surrogate decision making before death. N Engl J Med. 2010;365:1211-1218.

23 Choen J, Choen P: Applied multiple regression; Correlation analysis for behavioral Sciences. $2^{\text {nd }} e d$. Hillsdale, NJ: Lawrence Erlbaum, 1984, 513.

24 Alano GJ, Pekmezaris R, Tai JY, Hussain MJ: Factors influencing older adults to complete advance directives. Palliat Support Care. 2010;8:267-275.

25 Hamayoshi M, Kono A: Reliability and validity of the advance directive knowledge test and attitude survey for Japanese in local older residents. JACHN. 2013;16:32-40. Japanese.

26 Murphy CP, Sweeney M, Chiriboga D: An educational intervention for advance directives. J Prof Nurs. 2000;16:21-30.

27 Koran K, Kuroda K: Factors related to attitudes toward people with dementia: development of attitude toward dementia scale and dementia knowledge scale. Bulletin of Social Medicine. 2011;28:43-55. Japanese. 28 Ajzen I: The theory of planned behavior. Organ Behav Hum Decis Process. 1991;50:179-211.

29 Dipko LR, Xavier K, Kohlwes RJ: Advance directive group education in a VA outpatient clinic. Soc Work Health Care. 2008;38:93-106.

30 Sessanna L, Jezewski MA: Advance directive decision making among independent communitydwelling older adults: A systematic review of health science literature. J Appl Gerontol. 2008;127:486-510. 31 Heiman H, Bates DW, Fairchild D, Shaykevich S, Lehmann LS: Improving completion of advance directives in the primary care setting: A randomized controlled trial. Am J Med. 2004;117:318-324.

32 Detering KM, Hancock AD, Reade MC, Silvester $\mathrm{W}$ : The impact of advance care planning on end of life care in elderly patients: randomized controlled trial. BMJ. 2010;340:c1345. 